\title{
Uma Revisão de Literatura sobre a Definição de Projeto de Vida na Adolescência ${ }^{1}$
}

\author{
Letícia Lovato Dellazzana-Zanon* \\ Pontifícia Universidade Catílica de Campinas, Campinas, SP, Brasil \\ Lia Beatriz de Lucca Freitas \\ Universidade Federal do Rio Grande do Sul, Porto Alegre, RS, Brasil
}

\begin{abstract}
RESUMO
O objetivo deste trabalho foi realizar uma revisão de literatura de artigos sobre projetos de vida na adolescência produzidos de 2000 até 2012 a fim de investigar se pesquisadores interessados na temática apresentam ou não uma definição de projeto de vida e, em caso afirmativo, quais são essas definições. Realizou-se a busca dos artigos na Biblioteca Virtual de Saúde e no PsychNet da American Psychological Association. Consideraram-se apenas os artigos empíricos disponíveis online na íntegra. Identificaram-se 22 artigos. Os resultados indicaram que a maior parte dos estudos $(63,6 \%)$ não apresenta uma definição explícita de projeto de vida. Quando isto ocorre, observou-se que existe uma multiplicidade de definições. Entretanto, observaram-se alguns aspectos comuns entre as considerações sobre projetos de vida nos artigos encontrados.
\end{abstract}

Palavras-chave: projeto de vida; adolescência; revisão de literatura; desenvolvimento.

\begin{abstract}
A Literature Review on the Definition of Life Purpose in Adolescence

The aim in this research was to undertake a literature review of empirical studies about life purpose in adolescence produced between the years 2000 and 2012 to investigate whether researchers interested in the topic have or not a definition of life purpose and, if so, what are these definitions. The search for articles was done in the Virtual Health Library and in the PsychNet of American Psychological Association. Only papers fully available online were considered. Twenty-two papers were identified. The results indicated that most of the studies $(63.6 \%)$ does not provide an explicit definition of life purpose. When this occurs, it was observed a variety of definitions. However, there were some commonalities among the considerations of life purpose in the papers.
\end{abstract}

Keywords: life purpose; adolescence; literature review; development.

O projeto de vida tem sido foco de interesse de muitos pesquisadores tanto no Brasil (e.g., Abreu \& Alencar, 2012; Bock \& Liebesny, 2003; D’AureaTardeli, 2009; Miranda, 2007; Pratta \& Santos, 2007; Santos, 2002; Wagner et al., 2012) quanto em outros países (e.g., Bronk, Finch, \& Talib, 2010; Damon, 2009; Damon, Menon, \& Bronk, 2003; Francis \& Robbins, 2009; Hill, Burrow, O'Dell, \& Thornton, 2010; Rahman, 2004; Ynoub, \& Veiga, 2002). Entretanto, este não é um tema recente na psicologia. Autores clássicos da psicologia do desenvolvimento chamaram atenção para a importância deste assunto.
Erikson (1968/1976), por exemplo, considera a resolução bem-sucedida da crise de identidade do adolescente como a base para o estabelecimento do projeto de vida. Para esse autor, o projeto de vida tem um papel central na orientação dos objetivos fundamentais de um indivíduo e, por esta razão, é considerado um componente essencial da identidade e do bemestar individual. Assim, Erikson entende que a formulação de um projeto de vida é uma tarefa crucial de desenvolvimento. Embora relacionados, identidade e projeto de vida não são sinônimos: a identidade refe- 
re-se ao desenvolvimento de quem se é, ao passo que o projeto de vida diz respeito ao desenvolvimento do que se espera realizar durante a vida (Bronk, 2012).

Piaget (1964/2007), por sua vez, assinala a importância do programa ou plano de vida como fator constituinte da formação da personalidade e como parte do processo de integração do adolescente no mundo social adulto. Segundo Piaget e Inhelder (1955/1976), graças à construção das estruturas formais, o adolescente é capaz de raciocinar sobre hipóteses e ultrapassar as fronteiras do real. Esta capacidade é condição necessária (mas não suficiente) para a constituição de um plano de vida. Além de ser durante a adolescência que o indivíduo começa a se considerar no mesmo plano de igualdade dos adultos, é nesta fase também que ele passa a pensar em seu futuro dentro da sociedade. Ainda de acordo com esses autores, uma das características que distingue o adolescente da criança é justamente a capacidade de o primeiro realizar reflexões que ultrapassem o momento presente. Assim, além de construir teorias e sistemas, os adolescentes também constroem programas de vida.

Conforme Piaget (1964/2007), por meio da organização autônoma das regras, dos valores e da afirmação da vontade ocorre a construção da personalidade. Assim, há personalidade graças à construção de um programa de vida, o qual funciona como um instrumento de cooperação e como fonte de disciplina para a vontade. De acordo com Freitas (2011), a vontade, para Piaget, é um importante instrumento de autorregulação, uma vez que possibilita ao ser humano: (a) estabelecer fins prioritários para sua ação, hierarquizando valores, para constituir, então, sua própria escala de valores e (b) planejar suas ações, ou seja, construir projetos de vida. Ainda segundo essa autora, Piaget estabeleceu uma analogia entre a operação e a vontade: se a capacidade operatória liberta o sujeito das ilusões perceptivas, a vontade não o deixa subordinado aos seus interesses e desejos imediatos. Segundo Freitas, "o sistema de valores da pessoa é que define quais os fins de sua ação, ou seja, em que ações, em que projetos, ela investe suas energias" (p. 610). Assim, aquilo que uma pessoa mais valoriza ocupa o topo de sua escala de valores. Para Piaget (1954/2005), a escala de valores de um indivíduo é a "sua razão de ser", ou seja, é esta escala que dá sentido (direção e significado) a sua vida.

A ideia de que a adolescência é um período fértil do desenvolvimento humano para o estabelecimento de metas em relação ao futuro continua sendo atual. Para Almeida e Cunha (2003), a adolescência é considerada como uma fase de transição, a qual inclui reconstruir aspectos do passado e elaborar projetos de futuro. Martins, Trindade e Almeida (2003) entendem que, durante esse período, o jovem é convidado a construir seu projeto de vida. Bremm e Bisol (2008) acrescentam que, através da elaboração desse projeto, o adolescente pode construir novos significados sobre si e sobre o mundo, ressignificar os papéis que ocupava na infância e procurar novos referenciais além do grupo familiar. Para Damon (2009), a adolescência é um período no qual um pouco de autoanálise e experimentação são profícuos: "trata-se de um período de desenvolvimento transitório, uma espécie de baldeação na estrada rumo a uma autoidentidade madura" (p. 26). Por isso, esse autor afirma que os adolescentes devem gastar certo tempo pensando sobre si mesmos e sobre o futuro, tentando descobrir formas de dar conta de suas ambições e de seus interesses. Em síntese, autores contemporâneos também entendem que o estabelecimento de um projeto de vida é uma tarefa da adolescência.

Autores clássicos e contemporâneos da psicologia do desenvolvimento consideram importante que o adolescente elabore um projeto de vida. No entanto, pode-se observar que houve uma mudança na terminologia utilizada. Quando Piaget (1955/1976, 1964/ 2007) se refere a projetos de vida na adolescência, ele usa as palavras programa ou plano de vida (em francês, programme ou plan de vie). Atualmente, pesquisadores brasileiros interessados neste assunto (Cardoso \& Cocco, 2003; D’Aurea-Tardeli, 2010; Furlani \& Bomfim, 2010; Gonçalves et al., 2008; Leão, Dayrell, \& Reis, 2011; Miranda, 2007; Nascimento, 2006; Valore \& Viaro, 2007) têm utilizado os termos projeto ou projetos de vida. Nas pesquisas recentemente publicadas em inglês, a palavra utilizada é purpose. De acordo com o Shorter Oxford English Dictionary (2002, p. 2409), purpose tem os seguintes significa$\operatorname{dos}^{2}$, entre os quais nos interessam: (a) uma coisa a ser feita, um objeto a ser atingido, uma intenção, um objetivo, (b) a ação ou o fato de ter a intenção de fazer alguma coisa, resolução, determinação, (c) a razão para que algo seja feito, ou pela qual ele existe, o resultado ou o efeito pretendido. Assim, todas as vezes que apareceu a palavra purpose nos artigos em inglês, ela foi traduzida por projeto de vida. 
Projetar-se e pensar em si no futuro parece trazer benefícios para o sujeito (Damon, 2009; Minehan, Newcomb, \& Galaif, 2000), tais como: (a) conquista da felicidade, da realização e da satisfação pessoal e (b) a garantia de momentos de alegria nos bons tempos e momentos de resiliência nos momentos difíceis. Segundo Damon, ter projetos de vida claros pode proteger os jovens de possíveis comportamentos autodestrutivos, ao mesmo tempo em que os motiva no sentido de terem uma atitude positiva perante a vida. Sabese também que adolescentes que têm projetos de vida tendem a ficar mais afastados do uso de drogas tanto lícitas como ilícitas (Minehan et al., 2000). Assim, em consonância com Mariano e Savage (2009), entendese que estudar projetos de vida é fundamental para o progresso do conhecimento científico tanto em relação ao desenvolvimento do caráter como do bem-estar subjetivo. Conforme salientaram Damon, Menon e Bronk (2003), o projeto de vida não é um sonho de adolescente; ele realmente existe e pode ser investigado.

Todavia, construir projetos de vida na contemporaneidade não é uma tarefa fácil. Alguns autores (Damon, 2009; D'Aurea-Tardeli, 2009; La Taille, 2009; Margulis, 2001) consideram que isso é muito mais difícil hoje do que em outros momentos históricos. La Taille, por exemplo, chama atenção para alguns aspectos fundamentais em relação à construção de projetos de vida no mundo atual: a multiplicidade de possibilidades e a consequente necessidade de se fazer escolhas. Ter um projeto implica ter uma intenção, uma finalidade, um objetivo de realizar alguma coisa: "algo deverá ser feito, ser conquistado, ser adquirido, algo deverá se tornar realidade" (p. 43). Para isto, é necessário priorizar as possibilidades de realização e hierarquizá-las. Para esta hierarquização, há duas dimensões fundamentais: (a) afetiva e (b) cognitiva. A dimensão afetiva é responsável pelo valor (investimento afetivo) atribuído a cada meta e a cognitiva refere-se à capacidade de ordenar, função da inteligência. Assim, somente é possível hierarquizar possibilidades se existirem valores. De acordo com La Taille, a dificuldade de fixação e de conservação de valores, próprios da pós-modernidade, trazem consequências negativas para a construção de projetos de vida, pois se há um achatamento dos valores, ou "presença de valores que se inflacionam e se desinflacionam constantemente" (p. 74), como hierarquizar, escolher e estabelecer metas para o futuro? Assim como La Taille, pode-se pensar que a inconstância dos valores do homem pós-moderno prejudica a construção de projetos de vida. Esta seria uma razão a mais para que se continue a investigar este assunto.

Considerando-se que: (a) a adolescência é um período fértil do desenvolvimento para a construção de projetos de vida, (b) ter um projeto de vida pode trazer benefícios ao jovem e (c) há vários estudos que examinam projetos de vida na adolescência, os quais se fundamentam em diferentes perspectivas teóricas, é pertinente questionar-se: o que se entende por projeto de vida na atualidade? A fim de responder a esta questão, este estudo tem como objetivo realizar uma revisão de literatura para, especificamente, investigar os seguintes aspectos: (a) pesquisadores interessados na temática apresentam ou não uma definição de projeto de vida? e (b) caso se possa responder afirmativamente a essa pergunta, como os pesquisadores definem projeto de vida?

\section{MÉTODO}

Realizaram-se buscas em bases de dados em português e em inglês. A busca dos artigos em português foi realizada na Biblioteca Virtual de Saúde Psicologia (BVS-Psi) por meio das seguintes bases de dados: (a) Index Psi Periódicos Técnico-Científicos, (b) Periódicos Eletrônicos em Psicologia (PePSIC) e (c) Scientific Eletronic Library Online (Scielo). Os descritores utilizados foram: (a) projeto(s) de vida e adolescência e (b) projeto(s) vital(is) e adolescência. A busca em inglês foi feita na base de dados PsychNet da American Psychological Association (APA) com os seguintes descritores: (a) life purpose and adolescence, adolescent $\mathrm{e}(\mathrm{b})$, purpose in life and adolescence, adolescent.

Para fins deste estudo, consideraram-se apenas os artigos empíricos, produzidos desde o ano 2000 até o ano 2012, que estivessem disponíveis online na íntegra. Os descritores poderiam estar no título, no resumo ou nas palavras-chave dos artigos. Incluíram-se apenas artigos cujo objetivo principal fosse estudar projetos de vida. Por exemplo, excluíram-se artigos que mencionavam projetos de vida cujo foco, porém, era a gravidez na adolescência. Todos os artigos foram lidos na íntegra.

\section{RESULTADOS}

Em relação à busca de artigos em português, inicialmente, encontraram-se 50 artigos, distribuídos da seguinte forma: (a) 20 artigos no Index Psi Periódicos 
Técnico-Científicos, (b) nove artigos no Scielo, (c) 11 artigos no PePSIC. Descartando-se os artigos repetidos (19 artigos), restaram 30 artigos, dos quais 13 foram selecionados. Quanto à busca na base de dados PsychNet, encontraram-se 23 artigos, dos quais: (a) dois já haviam aparecido na busca em português, (b) nove não tinham como tema central o estudo de projetos de vida e, (c) três não estavam disponíveis online. Assim, dos 23 artigos encontrados, nove foram analisados. Considerando-se os artigos selecionados desta maneira, analisaram-se 22 artigos ao todo.

Tendo em vista o objetivo deste artigo, não se enfocaram os resultados dos estudos realizados; a análise dos artigos selecionados visou examinar que definição - se é que há alguma - tem sido usada pelos pesquisadores. Assim, organizaram-se os resultados da seguinte forma: (a) artigos que não apresentam nenhuma definição de projeto de vida, (b) artigos cujos autores citam várias definições sem adotar explicitamente uma definição de projeto de vida e (c) artigos que apresentam uma definição explícita de projeto de vida. Considera-se que uma definição está explícita quando os autores dos artigos apresentam uma definição precisa de projeto de vida, seja uma definição elaborada por eles mesmos seja uma definição de algum outro autor.

\section{Artigos sem uma definição de projeto de vida}

Cinco dos artigos selecionados não mencionaram nenhuma definição de projeto de vida ao longo do texto (Cardoso \& Cocco, 2003; Minehan et al., 2000; Pratta \& Santos, 2007; Valore \& Viaro, 2007; Zappe $\&$ Dias, 2011). O primeiro artigo, realizado por profissionais da enfermagem, abordou a questão do projeto de vida a partir da teoria de Paulo Freire e teve como objetivo investigar os projetos de vida de sete adolescentes de 14 a 18 anos de uma Unidade Básica de Saúde de Marília, São Paulo (Cardoso \& Cocco, 2003). O segundo estudo teve como objetivo investigar como a capacidade cognitiva do indivíduo, suas respostas de enfrentamento e seu projeto de vida predizem o consumo de drogas lícitas e ilícitas de 144 adolescentes de 12 a 17 anos estudantes de uma escola de Santa Bárbara, Califórnia (Minehan et al., 2000). O terceiro artigo articulou planos para o futuro, uso de drogas e relacionamento familiar a partir da opinião de 568 adolescentes usuários e não usuários de drogas de uma escola de São Carlos, São Paulo (Pratta \& Santos, 2007). O quarto estudo, realizado a partir da perspectiva psicanalítica, investigou as expectativas em relação ao projeto de vida e a relação entre profissão e sociedade no discurso de 114 adolescentes que estavam participando de um projeto de orientação profissional em Curitiba, Paraná (Valore \& Viaro, 2007). O último artigo foi uma pesquisa documental, por meio da qual se analisaram 736 fichas de identificação de adolescentes infratores do sexo masculino, que estavam cumprindo medida socioeducativa de internação em Santa Maria, Rio Grande do Sul (Zappe $\&$ Dias, 2011). Nesse estudo, buscou-se investigar se a medida socioeducativa de internação tem sido eficaz no sentido de oportunizar a reconstrução do projeto de vida de adolescentes infratores.

\section{Artigos que citam várias definições}

A segunda categoria de análise englobou nove artigos que não apresentaram uma definição precisa de projeto de vida (Borges \& Coutinho, 2010; Francis, 2000; Francis \& Robbins, 2009; Furlani \& Bomfim, 2010; Gonçalves et al., 2008; Graf \& Diogo, 2009; Hill et al., 2010; Locatelli, Bzuneck, \& Guimarães, 2007; Zonta, 2007). Observou-se que esses artigos apresentam ideias de diferentes autores sobre o tema, mas não chegam a uma definição precisa do que se entende por projeto de vida.

A pesquisa realizada por Borges e Coutinho (2010) visou compreender os sentidos do trabalho para adolescentes entre 15 e 17 anos de uma organização não governamental que estavam exercendo alguma atividade profissional pela primeira vez em Florianópolis, Santa Catarina. Para contextualizar projetos de vida, Borges e Coutinho utilizaram ideias de vários autores, os quais pontuam os seguintes aspectos: (a) a influência da infância, dos fatos marcantes de vida e do estilo de vida futuro na dimensão temporal dos projetos de vida, (b) embora se refira a um porvir e seja uma construção relacionada ao grupo social do qual o sujeito faz parte, o projeto de vida diz respeito ao passado e ao presente, (c) a futura trajetória produtiva do sujeito é estabelecida através da articulação entre escolha da profissão e projeto, (d) o projeto está em constante reelaboração, é resultado das possibilidades em que o sujeito está inserido, é dinâmico e é intersubjetivo e (e) o projeto é multidimensional, interliga passado e futuro e não pode ser considerado um acontecimento inesperado.

A pesquisa realizada por Francis (2000) teve como objetivo explorar a relação entre leitura da bíblia e 
projeto de vida em 25.888 adolescentes com idades entre 13 e 15 anos da Inglaterra e do País de Gales. Para Francis, um projeto de vida é central para o processo de construção de significado - o qual se opõe à falta de sentido. Ainda segundo esse autor, é o projeto de vida que faz a vida valer a pena e ajuda a prevenir o desespero, que pode levar ao suicídio. Em um estudo subsequente, Francis e Robbins (2009) estudaram a associação entre frequência de oração, projetos de vida e atitudes em relação a substâncias em 2.569 adolescentes com idades entre 13 e 15 anos da Inglaterra e do País de Gales. Nesse segundo trabalho, Francis e Robbins sugerem que o projeto de vida é um componente central do bem-estar psicológico. Entretanto, em nenhum dos dois artigos pode-se considerar que os autores explicitem uma definição de projeto de vida.

O estudo realizado por Furlani e Bomfim (2010) teve como objetivo analisar projetos de vida de 38 jovens entre 13 e 19 anos a partir da afetividade (sentimento e emoções) em relação ao ambiente no qual vivem: zona rural ou zona urbana do Ceará. Embora não apresentem uma definição de projetos de vida, as autoras assinalaram que construir projetos de vida é uma tarefa importante e um grande desafio, especialmente para os jovens: "o projeto de vida é, a nosso ver, uma questão de fundamental importância na vida de qualquer ser humano que se posiciona de maneira crítica e coerente diante de si mesmo e do meio em que vive" (p. 56).

Gonçalves et al. (2008), por sua vez, estudaram as representações sociais de 39 jovens entre 13 e 22 anos de Duque de Caxias, Rio de Janeiro, sobre seus problemas e as formas de enfrentá-los, relacionados aos seus projetos de vida. As pesquisadoras apresentaram as seguintes ideias: (a) projeto de vida está relacionado às transformações que ocorrem de uma geração para outra, seja pela confluência ou pela divergência de finalidades e (b) é através do projeto de vida que ocorre a adaptação do sujeito à realidade. Graf e Diogo (2009) investigaram os sentidos atribuídos por jovens às suas perspectivas de futuro, a partir da perspectiva da orientação profissional. Participaram desse estudo 49 adolescentes com idades entre 16 e 18 anos, alunos do terceiro ano do Ensino Médio de uma escola particular de Santa Catarina. Essas autoras apresentaram as seguintes considerações sobre projetos: (a) o projeto seria a "busca humana de superação de uma situação objetiva" (p. 73), (b) o projeto de ser está relacionado às perspectivas futuras e (c) a temporalidade é ontologicamente constitutiva do ser humano.

O estudo de Hill et al. (2010) teve como objetivo descrever como 229 adolescentes de duas cidades do centro-oeste dos Estados Unidos definem o construto projeto de vida e examinar se suas definições mostram diferenças individuais sistemáticas. A fim de apresentar o que entendem por projeto de vida, Hill et al. revisaram definições anteriores presentes na literatura e, a partir disso, assinalaram quais aspectos consideram como os mais importantes: (a) um indivíduo que tem um projeto de vida tem objetivos na vida e um senso de direção, sente que há sentido na vida no passado e no presente, possui crenças que dão um sentido para vida, e tem metas e objetivos para viver, (b) projeto é uma intenção estável e generalizada de realizar algo que é ao mesmo tempo significativo para o eu e que gera consequências para o mundo além do eu, (c) projeto refere-se à identificação de objetivos altamente valorizados e abrangentes, à realização do que é previsto para mover as pessoas mais perto de alcançar seu verdadeiro potencial, o qual, por sua vez, gera um senso de profunda realização, (d) projeto é um objetivo de vida central e auto-organizador, que organiza e estimula objetivos, gerencia comportamentos e proporciona uma consciência de sentido. A partir dessas definições, Hill et al. sugerem que três temas são particularmente relevantes: (a) projeto de vida é integralmente ligado ao estabelecimento de objetivos e a uma estrutura a partir da qual esses objetivos podem ser alcançados, (b) ter um projeto de vida deveria possibilitar uma sensação completude e (c) projeto geralmente é interpretado como tendo uma grande intenção pró-social, como servir aos outros ou algum outro bem maior. Apesar de discutirem a literatura sobre projeto de vida e de assinalarem temas comuns que consideram relevantes, Hill et al. também não apresentam explicitamente uma definição de projeto de vida.

Locatelli et al. (2007) realizaram uma pesquisa a fim de verificar se adolescentes percebem seus estudos atuais como um meio para alcançarem objetivos profissionais futuros, investigando qual a relação entre a motivação atual dos alunos e o seu projeto de vida. Participaram desse estudo 206 alunos do $3^{\circ}$ ano do Ensino Médio, da região norte do Paraná. Tais autores assinalaram os seguintes aspectos: (a) durante a adolescência, o indivíduo precisa ser capaz de estabelecer um projeto de vida e (b) ao final da adolescência, há a 
expectativa de que o indivíduo tenha tomado uma decisão quanto ao seu futuro, principalmente no que se refere à sua profissão.

Por fim, Zonta (2007) investigou quais são os objetivos que alunos de Ensino Médio de escolas públicas que participavam de grupos de orientação profissional em Curitiba, Paraná, incluem em seus projetos de vida. Zonta também não apresentou uma definição clara; ela apenas ressaltou a importância da consciência na construção do projeto de vida.

\section{Artigos com uma definição explícita de projeto de vida}

A terceira categoria de análise englobou todos os artigos cujos autores apresentaram uma definição precisa sobre o que entendem por projeto de vida (Bronk, 2008; Bronk et al., 2010; D’Aurea-Tardeli, 2010; Kiang, 2012; Leão et al., 2011; Marcelino, Catão, \& Lima, 2009; Mariano \& Savage, 2009; Nascimento, 2006). A seguir, apresentam-se os oito artigos classificados nesta categoria.

Observou-se que todos os artigos em inglês desta categoria (Bronk, 2008; Bronk et al., 2010; Kiang, 2012; Mariano \& Savage, 2009) adotam a definição que Damon et al. (2003) propuseram em um artigo de revisão de literatura: "projeto é uma intenção estável e generalizada de alcançar alguma coisa que seja significativa para o eu e que gere um compromisso produtivo para algum aspecto além do eu" (p. 121).

Bronk (2008) realizou uma pesquisa qualitativa na qual comparou as características compartilhadas entre dois grupos: (a) nove participantes que tinham um projeto de vida e (b) nove que não tinham um projeto de vida. Participantes de ambos os grupos tinham entre 12 e 23 anos e residiam nos Estados Unidos ou Canadá. O objetivo desse estudo foi investigar especificamente de que forma a humildade aparece entre os participantes. Bronk assinala que a definição de $\mathrm{Da}-$ mon et al. (2003) apresenta três aspectos importantes do projeto: (a) representa um objetivo final para o qual se pode fazer progressos, (b) é significativo para o eu, ou seja, o interesse em manter o projeto é voluntário e automotivado e (c) é significativo para as outras pessoas, ou seja, o interesse pessoal de ir em busca de um projeto inclui o desejo de contribuir para questões que vão além de si próprio.

Em um estudo subsequente, Bronk et al. (2010) pesquisaram a prevalência de projeto de vida em uma amostra de 64 adolescentes com altas habilidades e comparou-a com a prevalência de projeto de vida em uma amostra de 139 adolescentes típicos. Os participantes com altas habilidades eram do meio-oeste dos Estados Unidos, enquanto participantes típicos eram de diferentes regiões desse país. Alguns aspectos assinalados como importantes na definição de projeto de vida do estudo anterior foram refinados e são apresentados como três importantes dimensões: (a) intenção de avançar em direção a um objetivo final pessoalmente significativo, (b) a significação pessoal é sublinhada pela participação ativa, e (c) o projeto apresenta um desejo de fazer uma contribuição para o mundo mais amplo.

Kiang (2012) utilizou a metodologia do diário para identificar os tipos de eventos e atividades diárias na vida de180 adolescentes americanos asiáticos (média de idade $=14.9$ anos) que estão relacionados com uma consciência de projeto de vida. Os adolescentes receberam um diário com três páginas para cada dia, que deveria ser preenchido durante 14 dias. Solicitou-se aos adolescentes que escrevessem no diário antes de ir dormir e, que, após terem completado todas as páginas do diário, enviassem todo o material pelo correio para os pesquisadores. Mariano e Savage (2009) realizaram um estudo cujo objetivo principal foi gerar uma lista de estados positivos e de mecanismos de enfrentamento diante de obstáculos que acompanham a consciência de projeto de vida na adolescência. Participaram desse estudo 172 adolescentes (média de idade $=16.7$ anos) de diferentes etnias, sendo a maioria das áreas suburbana e rural da Califórnia. Mariano e Savage ressaltaram que ter um projeto de vida envolve pensar no futuro e manifesta-se potencialmente no comportamento. Ser uma pessoa que tem um projeto de vida requer a coordenação de um complexo conjunto de habilidades de longo prazo que incluem: (a) formar intenções, (b) ir em busca dessas intenções e (c) persistir em direção aos objetivos definidos, mesmo diante de obstáculos.

D'Aurea-Tardeli (2010) realizou um estudo sobre valores e expectativas para o futuro e manifestações sobre gostos e preferências de 52 jovens que frequentavam a $6^{\mathrm{a}}$ série do ensino fundamental de uma escola pública de Santos, São Paulo. Para construir sua definição de projeto de vida, D'Aurea-Tardeli lançou mão dos estudos de La Taille (2009) segundo o qual, para se construir um projeto de vida, devem-se priorizar alguns valores em detrimento de outros, consideran- 
do-se o que é melhor, evitando-se aquilo que pode ser nocivo para se alcançar determinada meta. D'AureaTardeli também salientou que a temporalidade é um componente importante da estrutura dos projetos de vida, pois a forma como os adolescentes projetam suas aspirações futuras sinaliza suas condições e seus estilos de vida. Considerando tais ideias, D'AureaTardeli define projeto de vida como "uma estrutura psicológica, que reflete as direções centrais do indivíduo, que determinam sua posição e pertencimento a uma sociedade concreta" (p. 61).

Leão et al. (2011) analisaram a relação que 245 adolescentes matriculados no Ensino Médio, no estado do Pará, estabelecem entre seus projetos de vida e a maneira como a escola contribui para a consecução desses projetos. Para explicar melhor esta questão, os autores basearam-se no conceito de presente estendido, uma dimensão de tempo na qual é possível fazer escolhas, um "horizonte existencial que, em certo sentido, inclui e substitui futuro e passado" (p. 1075). Assim, o futuro não é mais um limite a ser superado nem algo que orienta o presente, mas sim um horizonte "descontínuo e dinâmico, numa fragmentação da experiência com o tempo" (p. 1075). Feita esta distinção, Leão et al. apresentaram sua definição: "o projeto de vida seria uma ação do individuo de escolher um, entre os futuros possíveis, transformando os desejos e as fantasias que lhe dão substancia em objetivos passiveis de serem perseguidos, representando, assim, uma orientação, um rumo de vida" (p. 1071). Assim, tais autores salientam que o projeto de vida abarca os seguintes aspectos: (a) um plano de ação concreto quanto a algum domínio da vida, (b) um espaço de tempo mais ou menos amplo, (c) um campo de possibilidades relacionado ao contexto socioeconômico e cultural, o qual circunscreve suas experiências.

Marcelino, Catão e Lima (2009) compararam as representações sociais de 40 adolescentes, com idades entre 16 e 19 anos, que estudavam em escolas públicas e privadas de João Pessoa, Paraíba, quanto à construção de seus projetos de vida. Para esses autores, o projeto de vida é caracterizado como "a intenção de transformação da realidade, orientado por uma representação do sentido dessa transformação, em que são consideradas as condições reais na relação entre passado e presente na perspectiva de futuro" (p.547). Segundo esses autores, devem ser considerados os seguintes aspectos para definir o que são projetos de vida: (a) o projeto é vivenciado desde a infância, atra- vés do convívio familiar e comunitário, (b) a reflexão crítica sobre as vivências individuais é fundamental para que os sujeitos enxerguem possibilidade e impossibilidades de superar uma determinada realidade no futuro, (c) o projeto de vida é uma organização multidimensional, que abrange as dimensões socioafetiva, sociocognitiva e espaçotemporal articuladas entre si.

Por fim, Nascimento (2006), realizou uma pesquisa com 725 adolescentes entre 14 a 24 anos, matriculados no Ensino Médio de escolas públicas de Belém, Pará. Os objetivos dessa investigação foram: (a) compreender como esses adolescentes compartilham conhecimentos sobre seus projetos de vida e (b) qual a importância da escola para que tais projetos sejam alcançados. Para Nascimento, projeto de vida são as "aspirações, desejos de realizações, que se projetam para o futuro como uma visão antecipatória de acontecimentos, cuja base reside em uma realidade construída na interseção das relações que o sujeito estabelece com o mundo" (p. 59). A pesquisadora salienta ainda que: (a) projeto de vida e identidade são construídos reciprocamente, (b) projetos de vida são construídos desde a infância e ficam mais claros durante a adolescência graças a demandas biopsicossociais e (c) os projetos de vida são transformados de acordo com a história de vida e as novas relações estabelecidas pelo sujeito.

\section{DISCUSSÃO}

O objetivo deste artigo foi investigar como se define projeto de vida na contemporaneidade, por meio de uma revisão de literatura. Os resultados indicaram que a maior parte dos estudos $(63,6 \%)$ não apresenta uma definição explícita de projeto de vida. Quando isto ocorre (oito artigos), observou-se que existe uma multiplicidade de definições sobre projeto de vida: (a) intenção, no caso dos autores que usaram a definição de Damon et al. (2003), de alcançar alguma coisa (Bronk, 2008; Bronk et al., 2010; Kiang, 2012; Mariano \& Savage, 2009) e de transformação da realidade, segundo Marcelino et al. (2009); (b) estrutura psicológica (D'Aurea-Tardeli, 2010); (c) ação de escolher (Leão et al., 2011) e (d) aspirações (Nascimento, 2006). Pode-se pensar que isso tenha ocorrido por duas razões. A primeira diz respeito à própria natureza deste construto: projeto de vida tem sido considerado como um construto de difícil definição (M. A. P, Teixeira, comunicação pessoal, 2 de outubro de 2013). O relativo pequeno número de artigos que apresenta uma 
definição explícita é um indicador disso. A segunda refere-se ao fato de que os pesquisadores que se interessam por esta temática fundamentam seus estudos em diferentes perspectivas teóricas. Este dado é relevante porque a maneira como os pesquisadores definem projeto de vida tem implicações metodológicas e na forma de interpretação dos resultados.

Sem menosprezar a importância dessas diferenças, é preciso dizer que se encontraram também alguns aspectos em comum nas considerações que os autores dos artigos selecionados fizeram sobre projetos de vida. Dentre esses aspectos, destacam-se aqueles que podem servir, em estudos futuros, para refinar aquilo que se entende por projeto de vida: (a) fases do desenvolvimento, (b) sentido da vida, (c) contexto cultural e (d) inclusão do outro.

O primeiro aspecto comum a ser destacado refere-se à fase do desenvolvimento na qual inicia a construção do projeto de vida. Para alguns autores (Borges \& Coutinho, 2010; Marcelino et al., 2009; Nascimento, 2006), o projeto de vida começa a ser construído desde a infância. Borges e Coutinho (2010) e Marcelino et al. (2009) assinalam a importância do convívio familiar e comunitário para a elaboração do projeto de vida. Nascimento (2006) chama atenção para o fato de que, embora inicie na infância, o projeto de vida se torna mais claro durante a adolescência, graças a demandas biopsicossociais. Para Locatelli et al. (2007), a adolescência é a fase do desenvolvimento na qual o indivíduo deve ser capaz de estabelecer um projeto de vida. Alguns autores relacionaram a escolha profissional com o projeto de vida, afirmando que ao final da adolescência o indivíduo deve ser capaz de tomar uma decisão quanto ao seu futuro profissional (Borges \& Coutinho, 2010; Locatelli et al., 2007).

A importância do trabalho para o adolescente também foi assinalada por Piaget e Inhelder (1955/1976). De acordo com esses pesquisadores, o adolescente é, ainda, um indivíduo em formação que está começando a pensar em seu futuro dentro da sociedade. É por meio da inserção do adolescente no mundo do trabalho e da realização de uma tarefa efetiva que os sonhos e os projetos do adolescente se transformam em realidade. Do ponto de vista da capacidade de pensamento, a adolescência seria o período no qual a construção do projeto de vida se torna possível (Piaget \& Inhelder, 1955/1976). Entretanto, outro aspecto é crucial para construção do projeto de vida: a vontade. É graças à constituição da vontade que o adolescente é capaz de hierarquizar valores. Quais valores? Aqueles que ele aprendeu durante a sua vida, até o momento. Assim, o adolescente - ao contrário da criança - tem as condições necessárias, do ponto de vida do desenvolvimento cognitivo, para construir um projeto de vida. Tal construção, porém, não seria possível sem as vivências prévias - infantis - do sujeito.

Pode-se, então, pensar que a construção do projeto de vida acontece, de diferentes modos, ao longo de todas as fases do desenvolvimento humano: (a) inicia na infância, por meio da convivência familiar e social, (b) torna-se uma possibilidade concreta durante a adolescência, considerando-se os avanços cognitivos, afetivos e morais próprios deste período do desenvolvimento e (c) por seu caráter de projeção futura, envolve toda a vida adulta. $\mathrm{O}$ projeto de vida é especialmente importante durante a vida adulta, uma vez que ele pode funcionar como um guia para a vida do indivíduo. Assim, dependendo das ações do sujeito, o projeto de vida poderá ou não ser concretizado.

O segundo aspecto comum encontrado nos artigos selecionados refere-se ao sentido da vida. Entende-se por sentido, em consonância com Piaget (1954/2005), a direção e o significado que a vida pode ter de acordo com a escala de valores do indivíduo. Diferentes autores mencionaram o caráter de direção do projeto de vida (Bronk, 2008; Bronk et al., 2010; D'aureaTardeli, 2010; Hill et al., 2010; Kiang, 2012; Leão et al., 2011; Marcelino et al.,2009; Mariano \& Savage, 2009). Para alguns pesquisadores (D'aurea-Tardeli, 2010; Hill et al., 2010; Leão et al., 2011), o projeto de vida representa um rumo para a vida do individuo e é considerado como um aspecto central e autoorganizador. Marcelino et al. (2009), por sua vez, compreendem o projeto de vida como uma organização multidimensional, a qual abrange e articula as dimensões socioafetiva, sociocognitiva e espaçotemporal. Entretanto, é na definição de Damon et al. (2003) - utilizada nos estudos de Bronk (2008), Bronk et al. (2010), Kiang (2012) e Mariano e Savage (2009) - que se pode encontrar mais explicitamente o aspecto de direção do projeto de vida, na medida em que afirmam que o projeto é a intenção de alcançar algo significativo para si e que gere um compromisso produtivo para além de si.

Segundo Piaget e Inhelder (1955/1976), o projeto de vida é construído a partir da priorização de alguns valores em detrimento de outros. Como é possível realizar tal priorização? Somente se existir força de 
vontade (Piaget, 1954/2005). Segundo Freitas (2003), "há vontade quando, após oscilarmos entre um prazer tentador e um dever, optamos pelo dever" (p. 96). Disso decorre a ideia de que a vontade é um instrumento importante de autorregulação para o sujeito: é por meio da vontade que o sujeito tem condições de lidar com seus desejos imediatos e estabelecer o que, dentre todas as ações possíveis, é prioridade. Assim, pode-se pensar que a priorização e a hierarquização de valores, possível graças à constituição da vontade, explicam o caráter norteador e de direção do projeto de vida. Sem força de vontade, não seria possível construir um projeto de vida.

Os resultados deste estudo mostraram que além dos autores mencionarem a importância da direção do projeto de vida, eles fizeram referência ao significado do projeto de vida (Bronk, 2008; Bronk et al., 2010; Francis, 2000; Francis \& Robbins, 2009; Hill et al., 2012; Kiang, 2012; Mariano \& Savage, 2009). O aspecto do significado está claramente no conceito de Damon et al. (2003): a intenção de realizar algo deve ser significativa para o sujeito e o interesse em manter o projeto deve ser voluntário e automotivado. Francis (2000) assinalou que ter um projeto de vida é central para a construção de sentido. Esse autor salientou que o sentido decorrente do projeto de vida é o que faz a vida valer a pena e que ambos são importantes, na media em que podem ajudar na prevenção do suicídio, causado pela falta de sentido na vida. Esse resultado está em consonância com as ideias de La Taille (2009), o qual afirma que o suicídio é o "resultado trágico da falta definitiva de sentido para a vida" ( $p$. 74) e, na maioria das vezes, "o infeliz final de um longo processo de perda de sentido" (p. 70). Esse autor assinala ainda que a contemporaneidade é um tempo de crescente alta na taxa de suicídios, principalmente, entre os jovens.

Para alguns autores (Francis, 2000; Francis \& Robbins, 2009; Hill et al., 2010), o projeto de vida é um componente central do bem-estar psicológico. O bem-estar psicológico é composto por seis dimensões relacionadas ao potencial e às capacidades para enfrentar os desafios da vida (Siqueira \& Padovan, 2008). Uma dessas dimenções é o projeto de vida, considerado como os objetivos, as intenções e o senso de direção presentes na vida de um sujeito que tem um funcionamento positivo, os quais contribuem para a sensação de que a vida é significativa (Ryff, 1989; Ryff \& Keyes, 1995).
O terceiro aspecto comum diz respeito à importância do contexto cultural para a construção do projeto de vida. D'áurea-Tardeli (2010), Borges e Coutinho (2010) e Nascimento (2006), por exemplo, assinalaram que a base do projeto de vida está nas relações que o indivíduo estabelece com uma sociedade concreta, da qual ele faz parte. Gonçalves et al. (2008) e Marcelino et al. (2009) enfatizaram que a relação entre passado e presente deve ser considerada para a construção do projeto de vida, uma vez que ele diz respeito às transformações que ocorrem de uma geração para outra, portanto, mudanças de ordem social e cultural. Leão et al. (2011) destacaram que os objetivos do projeto de vida devem ser passíveis de serem perseguidos considerando-se o contexto socioeconômico e cultural. Por fim, Furlani e Bomfim (2010) assinalaram que é fundamental se posicionar de maneira crítica e coerente diante de si e do meio em que se vive para se ter um projeto de vida.

Essas considerações sobre o contexto cultural indicam que, embora o projeto de vida seja individual, ele é construído com base nos valores de uma determinada cultura e de um terminado momento histórico. O projeto de vida, portanto, não pode ser pensado sem se considerar o contexto cultural do adolescente. No entanto, sabe-se que não estamos vivendo em tempos propícios para a construção do projeto de vida. Ao contrário, conforme alerta La Taille (2009), "estamos em tempos de um mal-estar moral” (p. 160). Diante dessa realidade, construir projetos de vida na contemporaneidade não é uma tarefa fácil. Cientes das dificuldades do mundo contemporâneo, Cortella e La Taille (2009) chamam atenção para o fato de que sem uma história pessoal não há como construir um projeto de vida.

Por fim, o último aspecto comum refere-se à inclusão do outro no projeto de vida. Conforme a definição de Damon et al. (2003), a qual foi utilizada nos estudos de Bronk (2008), Bronk et al. (2010), Kiang (2012) e Mariano e Savage (2009), o projeto deve necessariamente gerar um compromisso produtivo para algum aspecto além do eu, ou seja, deve necessariamente incluir o outro. Bronk (2008) e Bronk et al. (2010) ampliaram essa definição e propuseram que o projeto de vida deve ser significativo para as outras pessoas, isto é, o interesse pessoal de ir em busca de um projeto inclui o desejo de contribuir para questões que vão além de si próprio. Nesse mesmo sentido, Hill et al. (2010) concluíram que o projeto tem sido com- 
preendido como tendo uma grande intenção prósocial, por exemplo, servir aos outros ou algum outro bem maior.

Todavia, alguns autores (Andrade, 2012; D'Aurea-Tardeli, 2008; Miranda, 2007) entendem que existem diferentes tipos de projeto de vida. Miranda (2007), por exemplo, distinguiu dois tipos de projeto: (a) conectados e (b) desconectados. Os primeiros incluem e reservam ao outro - outras pessoas, grupos ou instituições - um lugar central. Os segundos, por sua vez, apenas consideraram o outro como um meio para alcançar um fim. Assim, é plausível dizer-se que há pessoas que têm um projeto de vida no qual não incluem o outro.

\section{CONSIDERAÇÕES FINAIS}

Este estudo teve como objetivos investigar se pesquisadores contemporâneos que se dedicam à investigação de projetos de vida na adolescência apresentam ou não uma definição desse construto e, em caso afirmativo, quais são essas definições. Observou-se que a maior parte dos estudos revisados não apresentou uma definição de projeto de vida. Entre as poucas pesquisas que apresentaram uma definição explícita, observaram-se diferentes definições. Assim, considera-se que este estudo indica que definir projeto de vida é, de fato, um desafio. Entretanto, observaram-se alguns aspectos comuns entre as considerações sobre projetos de vida nos artigos encontrados.

Este estudo apresenta algumas limitações. Alguns artigos podem ter ficado de fora da análise em função: (a) das bases de dados consultadas, (b) do período de busca estipulado - 2000 a 2012, e (c) do fato de que se consideraram apenas artigos que estivessem disponíveis online. Além disto, não se analisaram os aspectos metodológicos dos artigos selecionados, uma vez que o objetivo deste artigo foi investigar especificamente a apresentação ou não de uma definição de projeto de vida. Mesmo assim, espera-se ter contribuído para o aprimoramento da definição de projeto de vida, discutindo-se alguns aspectos que têm sido considerados relevantes pelos pesquisadores interessados nesta temática.

Ter um projeto de vida é importante para o desenvolvimento saudável da vida. Entretanto, atualmente, a construção de um projeto de vida não é tarefa fácil. Considerando-se a necessidade de ajudar os jovens a refletirem sobre seu futuro na sociedade e a construi- rem seu projeto vida - uma vez que estamos vivendo em um tempo de incertezas e de falta de sentido -, espera-se que este estudo inspire outros pesquisadores a seguir investigando este tema. Sugere-se, ainda, que ações efetivas sejam realizadas na comunidade escolar para que tanto professores quanto pais se conscientizem da importância de trabalhar esta temática com seus alunos e filhos desde a infância.

\section{REFERÊNCIAS}

Abreu, E. F. \& Alencar, H. M. (2012). Projetos de vida e profissional: Um estudo com universitários da área da saúde. Psicologia da Educação, 35, 144-170.

Almeida, A. M. O. \& Cunha, G. G. (2003). Representações Sociais do Desenvolvimento Humano. Psicologia: Reflexão e Crítica, 16(1), 147-155.

Bock, A. M. M. \& Liebesny, B. (2003). Quem eu quero ser quando crescer: Um estudo sobre o projeto de vida de jovens em São Paulo. In: Ozella, S. A. Adolescências construídas a visão da psicologia sócio-histórica. (pp. 203-222). São Paulo: Cortez.

Borges, R. C. P. \& Coutinho, M. C. (2010). Trajetórias juvenis: Significando projetos de vida a partir do primeiro emprego. Revista Brasileira de Orientação Profissional, 11(2), 189-200.

Bremm, E. S. \& Bisol, C. A. (2008). Sinalizando a Adolescência: Narrativas de Adolescentes Surdos. Psicologia Ciência e Profissão, 28 (2), 272-287.

Bronk, K. C. (2012). A Grounded theory of the development of noble youth purpose. Journal of Adolescent Research, 27(1) 78-109.

Bronk, K. C. (2008). Humility among adolescent purpose exemplars. Journal of Research on Character Education, 6(1), 35-51.

Bronk, K. C., Finch, W. H., \& Talib, T. (2010). The prevalence of a purpose in life among high ability adolescents. High Ability Studies, 21(2), 133-145.

Cardoso, C. P., \& Cocco, M. I. M. (2003). Projeto de vida de um grupo de adolescentes à luz de Paulo Freire. Revista Latino-Americana de Enfermagem, 11(6), 778-785.

Cortella, M. S. \& La Taille, Y de. (2009). Nos labirintos da moral. (5 ed.). Campinas: Papirus 7 Mares.

D'Aurea-Tardeli, D. (2010). Identidade e Adolescência: Expectativas e valores do projeto de vida. Revista Eletrônica Pesquiseduca, 2(3), 65-74.

D'Aurea-Tardeli, D. (2009). Adolescência, personalidade e projeto de vida solidário. In Y. de La Taille \& M. S. de S. Menin (Eds.). Crise de valores ou valores em crise? (pp. 70-88). Porto Alegre: Artmed. 
Damon, W. (2009). O que o jovem quer da vida? Como pais e professores podem orientar e motivar os adolescentes. (J. Valpassos, Trans.) São Paulo: Summus.

Damon, W., Menon, J., \& Bronk, K. C. (2003). The development of purpose during adolescence. Applied Developmental Science, 7(3), 119-128.

Freitas, L. B. L. (2003). A moral na obra de Jean Piaget: Um projeto inacabado. São Paulo: Cortez.

Freitas, L. B. L. (2011, julho). Vontade: Instrumento de autorregulação emsituações de conflito. In Anais do II Congresso de Pesquisas em Psicologia e Educação Moral COPPEM. Campinas, SP.

Erikson, E. H. (1976). Identidade, juventude e crise. (A. Cabral, Trans.). Rio de Janeiro: Zahar. (Original published in 1968)

Francis, L.J. (2000). The relationship between Bible reading and Purpose in life among 13-15 years old. Mental Health, Religion and Culture 3, 27-36.

Francis, L. J. \& Robbins, M. (2009). Prayer, purpose in life, and attitudes toward substances: A study among 13-to 15-year-olds in England and Wales. Counselling and Spirituality / Counseling et Spiritualité, 28(2), 83-104.

Furlani, D. D, \& Bomfim, Z. A. C. (2010). Juventude e afetividade: Tecendo projetos de vida pela construção dos mapas afetivos. Psicologia \& Sociedade, 22(1), 5059.

Gonçalves, H. S., Borsoi, T. S., Santiago, M. A., Lino, M. V., Lima, I. N., \& Federico, R. G. (2008). Problemas da juventude e seus enfrentamentos: um estudo de representações sociais. Psicologia e Sociedade, 20(2), 217-225.

Graf, L. P., \& Diogo, M. F. (2009). Projeções juvenis: Visões ocupacionais e marcas de gênero. Revista Brasileira de Orientação Profissional, 10(1), pp. 71-82.

Hill, P. L., Burrow, A. L., O’Dell, A. C., \& Thornton, M. A. (2010). Classifying adolescents' conceptions of purpose in life. The Journal of Positive Psychology, 5(6), 466-473.

Kiang, L. (2012). Deriving daily purpose through daily events and role fulfillment among Asian American youth. Journal of Research on Adolescence, 22(1), 185198.

La Taille, Y de. (2009). Formação ética: Do tédio ao respeito de si. Porto Alegre: Artmed.

Leão, G., Dayrell, J. T., \& Reis, J. B. (2011). Juventude, projetos de vida e ensino médio. Educação \& Sociedade, 32(117), 1067-1084.

Locatelli, A. C. D, Bzuneck, J. A., \& Guimarães, S. E. R. (2007). A motivação de adolescentes em relação com a perspectiva de tempo futuro. Psicologia: Reflexão e Crítica, 20 (2), 268-276.
Marcelino, M. Q. S., Catão, M. F. F. M., \& Lima, C. M. P, (2009). Representações sociais do projeto de vida entre adolescentes no ensino médio. Psicologia: Ciência $e$ Profissão, 29(3), 544-557.

Margulis, M. (2001). Juventud: Una aproximación conceptual. In S. D. Burak (Ed.), Adolescencia y juventud en América Latina (pp. 41-56). Cartago: Libro Universitário Regional.

Mariano, J. M. \& Savage, J. (2009). Exploring the language of youth purpose: References to positive states and coping styles by adolescents with different kinds of purpose. Journal of Research in Character Education, 7(1), 1-24.

Minehan, J. A., Newcomb, M. D., \& Galaif, E. R. (2000). Predictors of adolescent drug use: Cognitive abilities, coping strategies and purpose in life. Journal of Child \& Adolescent Substance Abuse, 10(2), 33-52.

Martins, P. O., Trindade, Z. A., \& Almeida, A. O. (2003). $\mathrm{O}$ ter e o ser: Representações sociais da adolescência entre adolescentes de inserção urbana e rural. Psicologia: Reflexão e Crítica, 16(3), 555-568.

Miranda, F., H., F. (2007). Projetos de vida na adolescência: Um estudo na área da ética e da moralidade. Unpublished masther's thesis. Programa de Pós-Graduação em Psicologia, Universidade Federal do Espírito Santo. Vitória, Brasil.

Nascimento, I. P. (2006). Projeto de vida de adolescentes do ensino médio: Um estudo psicossocial sobre suas representações. Imaginário, 12(12), 55-80.

Piaget, J., \& Inhelder, B. (1976). Da lógica da criança à lógica do adolescente. (D.M. Leite, Trans.). São Paulo: Livraria Pioneira. (Original published in 1955)

Piaget, J. (2007). Seis estudos de psicologia. (24 ${ }^{\mathrm{a}}$ ed.). (M. A. M. D’Amorim \& P. S. L Silva, Trans.). Rio de Janeiro: Forense Universitária. (Original published in 1964)

Piaget, J. (2005). Inteligencia e Afectividad. (M. Carretero, Trans.). Buenos Aires: Aique Grupo Editor. (Original published in 1954)

Pratta, E. M. M. \& Santos, M. A. (2007). Opiniões dos adolescentes do ensino médio sobre o relacionamento familiar e seus planos para o futuro. Paidéia, 17 (36), 103-114.

Ryff, C. D. \& Keyes, C. L. M. (1995). The structure of psychological well being revisited. Journal of Personality and Social Psychology, 69, 719-727.

Ryff, C. D. (1989). Happiness is everything, or is it? Explorations on the meaning of psychological well being. Journal of Personality and Social Psychology, 57, 10691081.

Rahman. T. (2004). Parental divorce and purpose in life of adolescents in Bangladesh. The International Forum for Logotherapy, 27, 77-79. 
Santos, M. I. (2002). Projeto de vida e perspectivas futuras: Um estudo sobre as representações sociais do tempo futuro presente. Unpublished masther's thesis. Programa de Pós-Graduação em Psicologia da Educação. Pontifícia Universidade Católica de São Paulo. São Paulo, Brasil

Shorter Oxford English Dictionary (2002). (5 $5^{\text {th }}$ ed.). New York: Oxford University Press.

Siqueira, M. M. M. \& Padovan, V. A. R. (2008). Bases teóricas de bem-estar subjetivo, bem-estar psicológico e bem-estar no trabalho. Psicologia: Teoria e Pesquisa, 24(2), 201-209.

Valore, L. A., \& Viaro, R. V. (2007). Profissão e sociedade no projeto de vida de adolescentes em orientação profissional Revista Brasileira de Orientação Profissional, 8(2), 57-70.

Wagner, A., Tronco, C. B., Gonçalves, J. S., Demarchi, K. A., \& Levandowski, D. C. (2012). Projetos para os filhos e estratégias de socialização: A perspectiva de pais e mães. Psicologia \& Sociedade, 24(1), 122-129.

Ynoub, R. \& Veiga, C. (2002). Proyecto de vida y construcción del proyecto ocupacional en adolescentes en al- to riesgo psicosocial. Acta Psiquiátrica y Psicológica de América Latina, 48(1-4), 50-60.

Zappe, J. G. \& Dias, A. C. G, (2011). Grades não prendem pensamentos: Limites da institucionalização na reconstrução do projeto de vida do adolescente. Psico PUCRS, 42(2), 220-227.

Zonta, A. G. (2007). A construção do projeto de vida do aluno da rede pública de educação. Psicologia e Argumento, 25(50), 259-266.

\section{Notas:}

1 Artigo elaborado a partir da tese de Letícia Lovato Dellazzana-Zanon, intitulada "Projetos de vida na adolescência: comparação entre adolescentes que cuidam e que não cuidam de seus irmãos menores". Universidade Federal do Rio Grande do Sul, 2014.

Apoio: Coordenação de Aperfeiçoamento de Pessoal de Nível Superior

2 Tradução das autoras. 